\title{
ALGUNAS NOTAS EN TORNO A LOS UNIVERSOS NARRATIVOS DE LA NAVE DE LOS LOCOS Y LA ÚLTIMA NOCHE DE DOSTOIEVSKI DE CRISTINA PERI ROSSI
}

\section{SOME NOTES REGARDING THE NARRATIVE UNIVERSE OF FOOLS SHIP AND THE LAST NIGHT OF DOSTOIEVSKI CRISTINA PERI ROSSI}

\section{RESUMEN}

La obra de Cristina Peri Rossi ha sido ampliamente examinada por la crítica especializada; y es que, sus universos narrativos resultan ser fuentes inagotables no solo en la comprensión de las estrategias estéticas y de los complejos temáticos que configuran el perfil escritural de la autora, sino que muestran un fundido artístico en que la literatura establece permanentes puentes con la vida, fraguando unas construcciones ficcionales que se confunden con las propias expresiones de la condición humana. En este artículo, desde una perspectiva fenomenológica y hermenéutica, se reflexiona en torno a dos temas recurrentes en la obra de Peri Rossi: exilio y azar; vistos a partir de dos obras fundamentales de la autora: La nave de los locos y La última noche de Dostoievski, con el interés de comprender el esfuerzo exploratorio que hace la escritora hacia el psicologismo de los personajes, cuya expedición se constituye en testimonio tanto de sus búsquedas estéticas, como de los diálogos permanentes que su obra establece con esa vida recreada en múltiples manifestaciones del arte. Estas reflexiones se acompañan del testimonio que la misma Peri Rossi ha formulado en discursos y entrevistas, convirtiendo a ambos documentos en instancias metodológicas válidas para la investigación literaria.

Palabras clave: azar; Cristina Peri Rossi; exilio; literatura y vida; universos narrativos.

\section{ABSTRACT}

The Cristina Peri Rossi's work has been extensively examined by specialized critics; their narrative universes turn out inexhaustible sources, not only in the understanding of the aesthetic strategies and the complexes topics that make up the author's scriptural profile, but also show an artistic fusion in which literature establishes permanent bridges with life, forging fictional constructions that are confused with the own expressions of the human condition. In this article, from a phenomenological and hermeneutic perspective, it reflects on two recurring themes in Peri Rossi's work: exile and random; seen from two fundamental works of the author: La nave de los locos and La última noche de Dostoievski, with the interest in understanding the exploratory effort the writer makes, towards the psychologism of personages, whose expedition is constituted in testimony so much of its aesthetic pursuits, as of the permanent dialogues his work establishes with the life recreated in multiple manifestations of art. These reflections are accompanied by testimony the same Peri Rossi has made in speeches and interviews, turning both documents into valid methodological instances for literary research.

Keywords: Cristina Peri Rossi; exile; narrative universes; literature and life; random. 


\section{INTRODUCCIÓN}

Es evidente que el psicologismo con el cual son tratados los personajes de Peri Rossi, recrea en una vertiente de doble articulación psicoanalítica no solo el terreno inconsciente -el mito personal- de la propia autora; sino expresan las patologías ocultas de seres anti heroicos que luchan por encontrarse y entenderse a sí mismos. Exilio, adicción, transgresión, deslocalización y fragmentariedad son categorías de esquemas humanos que experimentan crisis de identidad, expresando permanentemente ambivalencias, dualidades y complejas formas de definición y aceptación dentro de universos puestos en tensión a partir de instancias limítrofes y caóticas que huyen a toda posibilidad de certeza; pero también, a toda posibilidad de alienación. Personajes-seres que ilustran y padecen (alegóricamente) el exilio geográfico, las diferencias sexuales, las exclusiones culturales, la trasgresión política, la marginación histórica, la distancia generacional, la ruptura estética; en fin, tipos humanos al margen que representan una profunda pérdida de identidad, una permanente -y a vecesimperceptible frustración por los proyectos existenciales inconclusos, utópicos; $\mathrm{y}$, una dislocación del sentido, trascendiendo así, en modelos de esquizofrenia patológica con los cuales, además del mapa narrativo, se configura el mundo contemporáneo. En este sentido, refiere Sánchez lo siguiente:

...las obsesiones de los personajes rossinianos son de diversa naturaleza y apelan a la vulnerabilidad de éstos. Hay personajes obsesionados (o adictos) con el amor, el juego, las drogas, el trabajo, la rutina; personajes obsesionados por encontrar un espacio propio, por recuperar las tierras del Paraíso o combatir las múltiples formas del poder. Estos personajes persiguen la felicidad, recorriendo diversas vías para alcanzarla. Todos desean encontrar la armonía y la calma, la plena realización de sí mismos. El sentimiento de carencia es común a todos ellos: se parte de la falta para contar una historia y esa ausencia es la que motiva la búsqueda incesante y obsesiva de la felicidad. La naturaleza de ese vacío es misteriosa, pero la causa más probable proviene del orden de este mundo, un orden establecido mediante normas impositivas a las cuales los personajes se ven obligados a someterse. Dicho orden familiar, socio-político o cultural coarta la libertad del individuo y provoca angustia y malestar en él. De ahí que muchos personajes rossinianos opten por alejarse de la realidad mediante la insistente realización de tareas que llegan a hacerse imprescindibles y obsesivas. Otra forma de evasión de la realidad es el sueño o la ensoñación, espacio acogedor la mayoría de las veces, donde es posible encontrar indicios o revelaciones. Estas formas de evadirse de la realidad no eximen a los personajes de la angustia, ya que éstas mismas provocan otra clase de inquietudes. (Sánchez 2007:476-477).

En el aspecto psicológico interesa advertir cómo dicho aspecto se funde con el universo narrativo a través del lenguaje. Así, lo psicológico y lo textual, se realimentan inextricablemente (casi laberíntico) y fluyen, amalgamados, por medio de un discurso que proyecta tanto los mecanismos del inconsciente como el conjunto de pulsiones palpitantes en la imaginación, en los sueños y en las conductas, materializándose desde un lenguaje que recrea, expresa e ilustra el espacio narrativo en consonancia con la condición humana. En síntesis, el mundo interior de las entidades que se fabulan y diluyen en el texto dialogan-como en la vida misma- con las expectativas, búsquedas, fantasmas interiores y subjetividades de un yo creador (y también de un yo lector). En esta suerte de diálogos, son válidas las afirmaciones de (Gallego 2014:178), quien nos dice: "La obra literaria le ofrece al lector la posibilidad de un encuentro entre dos interioridades, que probablemente activan sus fantasías inconscientes". 


\section{METODOLOGÍA}

La investigación emprendida, se asume desde una perspectiva hermenéutica caracterizada por un interés comprensivo-interpretativo que consolida en la explicación argumentada, dos núcleos temáticos recurrentes en la obra de Cristina Peri Rossi como lo son el exilio y el azar. Esclarecedoras resultan las observaciones de Ricoeur en torno al ejercicio hermenéutico como instancia propicia para la búsqueda de sentidos y significados en el texto:

El término interpretación se puede aplicar no a un caso particular de la comprensión, el de las expresiones escritas de la vida, sino al entero proceso que abarca explicación y comprensión. La interpretación como dialéctica de explicación y comprensión puede luego hacerse remontar a las etapas iniciales del comportamiento interpretativo ya en acción en la conversación. No se define por una clase de objetos -los signos "inscritos", en el sentido más general del término- sino por una clase de proceso: la dinámica de la lectura interpretativa. (Ricoeur 1975:74)

En atención a estos planteamientos, resulta válido precisar que el estudio sigue una doble articulación teórica-metodológica: por una parte, interesa advertir cómo se construye el universo narrativo en las dos obras seleccionadas, las cuales resultan fundamentales dentro de la propuesta narrativa de esta escritora; por la otra, el propósito se centra en examinar el tratamiento de los dos temas al objeto de estudio, en las precitadas obras. En ambos desafíos, el fundamento no solo se encuentra en los aportes de la crítica precedente, además se ubica en consideraciones derivadas del psicoanálisis y en observaciones hechas a los propios productos literarios.

De esta forma, nos aproximamos tanto al universo narrativo, como a las búsquedas escriturales de Peri Rossi, todo ello a través de exploraciones constantes al terreno psicológico, bien del acto creativo o de la obra creada. Estas excursiones permiten develar la existencia de un puente con permanentes transiciones que enlazan la vida con la literatura.

Es precisamente este cruce constante en la obra de esta autora lo que permite hacerse cargo, como valor agregado, del aporte de las entrevistas y de los discursos como documentos que coadyuvan más que con el carácter argumentativo de los planteamientos, con el ejercicio procesual de la investigación literaria.

\section{RESULTADOS Y DISCUSIÓN}

\section{El exilio en La nave de los locos}

En "La nave de los locos", hay una metáfora de la vida que se consolida en la presencia de un viaje interior dentro de otro viaje. Se evidencia un tono de dilación descriptiva que se consolida en intertextualidades permanentes. Así, la obra literaria es acompañada de otros discursos o géneros del arte que dialogan en la estructuración u organización del tejido textual. Su misma organización narrativa da la idea de un barco, cuyo recorrido imaginario reconstruye la experiencia de un viaje, tal vez de un sueño, multiforme cargado además de múltiples y alegóricas experiencias que validan un interdiálogo de texturas y escritores.

Es evidente que la obra tiene como hilo conductor el tema del exilio, el cual va moviendo dosificadamente sus coordenadas teóricas (extranjero, desamparo, nostalgia y desarraigo) alrededor de una incesante dialéctica entre pérdida y conquista. De esta forma, la existencia misma del viaje como trasiego, tránsito, fugacidad y fluir temporal se constituye en una metáfora propia de la vida y del universo que viene a expresar la extranjeridad como condición "sospechosa", 
precaria y transitiva capaz no solo de suscitar una problemática de identidad con el o lo otro (distinto); sino de mostrar cómo la propia identidad entra en crisis. Atendiendo a estos planteamientos, Corbatta plantea en un interesante estudio lo siguiente:

Las metáforas del viaje son numerosas. Comienzan con el juego entre viaje experimentado y viaje leído..., O el viaje como desplazamiento en el espacio que conlleva también una vuelta al pasado... Pero sobretodo se trata de un viaje interior..., nunca terminado... El teatro... y también los sueños constituyen otras formulaciones del viaje... Finalmente, el viaje adquiere un valor omnicomprensivo visto como una alegoría de la vida humana; pasa, de ser accidente a convertirse en esencia ("Todos somos exiliados de algo o alguien... En realidad, esa es la verdadera condición del hombre", 106); de allí que todo paraíso, de existir, tendría la forma de la nostalgia. (Corbatta 1994:171-172)

El tema del viaje, y dentro de éste, el exilio adquiere en esta obra una dimensión autobiográfica que tiene la forma bien de una constante política o de un imaginario, expresión del inconsciente. En este sentido, el exilio adquiere una doble articulación (tal como señalara en 1991 la misma Peri Rossi): es una instancia simbólica que implica, necesariamente, la reconstrucción del pasado para mitigar la condición de desplazado en el tiempo y en el espacio; y aspirar, entonces, la posibilidad de recobrar la condición de identidad; pero, además, es una instancia narrativa que hace del discurso un tapiz de múltiples diálogos que se concentran bien en la necesidad de contar, o bien, en la sensibilidad para abordar los conflictos inherentes a la humanidad. Resulta conveniente, en relación a estas ideas, retomar los interesantes planteamientos de Szurmuk, cuando expresó.
Equis representa el exilio, pero a la vez la imposibilidad de la identidad como fenómeno inequívoco, universal. Despojado de la relación con el lugar donde ha crecido, Equis es una incógnita, un ser humano con un cuerpo y un lenguaje que deben ser forzados a significar fuera del espacio donde lo hacían... La posicionalidad del extranjero resulta clave en la novela de Peri Rossi donde la mayoría de los personajes son extranjeros en la definición más amplia del término: no pertenecen a los núcleos de la sociedad, son identificados con lo abyecto... De su vida anterior, Equis ha traído su cuerpo y su lengua. Ha perdido su hogar y lo reconstruye simbólicamente en los diferentes lugares en que se instala, pero en última instancia su cuerpo y su lenguaje son su morada. Ambos- el cuerpo y el lenguaje- están en crisis en la novela... El exilio en la novela aparece de dos maneras: por un lado, como la pérdida de la identidad, la casa, el lugar, pero por otro como el modo de desnudar los otros exilios... La novela también pone en tela de juicio la crisis de representación que supone escribir desde el exilio. En La nave de los locos se cuestiona la existencia de estos sujetos completos y desarrollados y se propone, en cambio, una concepción fragmentaria del sujeto... Equis representa el exilio, pero a la vez la imposibilidad de la identidad como fenómeno inequívoco, universal. (Szurmuk 2003:92-97)

Desde ambas dimensiones, lo simbólico y lo narrativo, son mediados por un inconsciente que reconstruye la experiencia del exilio como un duelo "necesario" para generar nuevas etapas, nuevos crecimientos. De esta forma, la vida es entendida como un viaje incesante y el hombre como un transeúnte, inmigrante permanente. Ambas ideas reafirman la condición de exilio y transitoriedad. En este punto, los aportes teóricos obtenidos de ámbitos sociológicos o psicológicos, 
hacen reconocer en la migración bien el tránsito de un lugar a otro (con todas las implicaciones sociales y personales que subyacen en su naturaleza) o bien, el necesario recorrido humano como posibilidad de desarrollo (el individuo se construye enfrentando/superando un conjunto de migraciones por las patrias interiores).

En esta suerte de constante viaje, indistintamente desde las razones que lo motiven, el exilio se figura como una experiencia traumática que incluye períodos de dolor, frustración, desorganización y lucha interior (por el temor a perder contacto con lo familiar, por el sentido de ambivalencia e inestabilidad entre lo conocido que se ha dejado y lo desconocido que se encontrará o "enfrentará"; y, por los sentimientos encontrados entre los afectos que se quedan y aquellos con los que se parte); pero también, se entiende como posibilidad de enriquecimiento personal y cultural (se nutre la identidad, intensifica la visión de mundo y enriquece el carácter comprensivo de lo propio y ajeno). Valen en este planteamiento, las afirmaciones de Aventín, quien atendiendo a los aportes de León y Rebeca Grinberg, señala lo siguiente:

En su obra Psicoanálisis de la migración y del exilio, León y Rebeca Grinberg señalan la puesta en riesgo de la identidad y su posible fragmentación como consecuencia inmediata que tiene el exilio en el individuo, ya que supone la pérdida de los objetos más significativos y valorados: "personas, cosas, lugares, idioma, cultura, costumbres, clima", etc. Tras la marcha se inicia un proceso de duelo que se vive como "un cambio catastrófico en la medida en que ciertas estructuras se transforman en otras a través de momentos de dolor, desorganización y frustración". Sin embargo, "estos momentos una vez superados y elaborados, darán la posibilidad de un verdadero crecimiento y evolución enriquecida de la personalidad". (Aventín 2011:47)

Visto de este modo, la condición de exilio permite poner en contacto nuevos y viejos códigos, contextos, conquistas y pérdidas que, pese a las distintas oportunidades o posibilidades que se despliegan ante el desafío de la migración, no dejan de concebir al exiliado como transgresor. En La nave de los locos, Equis es testimonio de un conjunto de coordenadas conceptuales en torno al exilio, él es un símbolo; pero también es un universo narrativo; es un fragmento y con ello, la expresión más fehaciente de ruptura, fracturando así, todas las identidades "posibles" e instaurando, en su lugar, la incertidumbre, la indeterminación de seres, sexualidades, destinos, proyectos políticos, geografías, recuerdos, espacios, tiempos y órdenes. Nos dice Sánchez:

Equis, por tanto se erige como figura representante del hombre exiliado, el cual se encuentra despojado de un espacio y un tiempo conocidos e identificadores, despojado, también, de nombre... y de futuro... Equis protagoniza un oscuro periplo, a bordo de la simbólica nave de los locos, en el transcurso del cual muestra mediante sus reflexiones, sus reacciones y sus encuentros y desencuentros, la experiencia dolorosa y formativa del exilio, no exenta de humor e ironía... La ausencia de espacio propio provoca el extrañamiento y dislocación del propio exiliado respecto a sí mismo. Equis refleja una identidad borrosa y múltiple, como múltiple y pluridimensional es el concepto de exilio... Equis es el extranjero, el exiliado, el extraño, el excéntrico, aquél que no tiene identidad ni pretende simularla, ya que no desea estar determinado por ella... Equis es un ser ajeno, no se inscribe en ninguno de los índices clasificatorios de la sociedad excepto en aquel que remite al exilio y la marginación. (Sánchez 2007:481-485) 
Este marco teórico-reflexivo (por cierto, ampliamente abordado por teóricos, críticos e investigadores de la obra de Peri Rosssi), nos permite dilucidar cómo en La nave de los locos, el tema del exilio además de ser el hilo conductor del discurso narrativo, es el hilo conductor del discurso simbólico. Con él, se interpela permanentemente la conciencia que ya no es solo el aliento creador, sostenedor del universo creado; sino que ahora adquiere las dimensiones de crítica y reacción para mostrar "la vida emocional inestable" del inmigrante, el sentimiento ante el "monstruo de las dictaduras" y la ironía con la cual el dolor es transmutado en sarcasmo y cruel humor negro. De esta forma, La nave de los locos emprende un viaje por diversas categorías, símbolos, lugares de lectura, discursos, escrituras, textualidades e imágenes; en fin, un desplazamiento dentro de otro que, en infinita recurrencia, va tejiendo la idea de un exilio, la cual se va desplazando desde una perspectiva de marginación y exclusión hacia una noción de liberación y determinación (Cid 2012:86).

\section{El juego y otros azares en La última noche de Dostoievski}

En "La última noche de Dostoievski", predominan un conjunto de aspectos que hacen de la obra un universo complejo en que el azar instaura, paradójicamente, las únicas certezas válidas de un tejido narrativo que a veces es juego y otras es inconsciente, que a veces es Jorge y otras tantas es el intertexto Dostoievski.

En esta suerte de tejido textual, resulta interesante detenerse en cuatro aspectos que recrean una aparente y "normal" historia que esconde en las veredas y atajos de su subtexto, una cotidianidad narrada que es a un mismo impulso, deseo, obsesión, frustración y pérdida, mostrando así una otra cara de lo que somos, una otra mirada de lo que sentimos... El juego inviste de otra moral, del secreto, de lo pecaminoso, prohibido $\mathrm{y}$ penoso. No solo por la máscara de una conciencia adictiva que se esfuerza en ocultar, sino porque con el juego, con el azar -para precisar la atmósfera- Jorge pretende, extraordinariamente, "matar a Dios".

El triunfo del azar además de representar la caída de toda posibilidad de certeza, actúa como una sensación sublime de controlar el destino (esto ilustra el ideal de incertidumbre, ícono fundamental de la postmodernidad), y así, hombre y juego recrean una metáfora en donde un pequeño Dios controla las reglas que rigen el universo de la máquina, de las cartas, de los dados..., más que el dinero, importa con el azar, vencer al destino. Sentencia Peri Rossi -desde la voz de Jorge, con un aire de justificación y reivindicación, "todos somos adictos", es el mismo espíritu que devela la universalidad de la condición humana, ésa en la cual también es evidente que todos seamos exiliados. La voz de Jorge nos resulta esclarecedora y permite advertir, en la propia acción narrativa, estas ideas:

Nada que ver con el verdadero jugador, un solitario que detesta la compañía, las aglomeraciones, y que necesita toda su concentración para enfrentarse al azar... (Peri Rossi 1992:9)

Lo que busco, Carlos, es muy sencillo de decir: ganar una y otra vez, saltar la banca, destruir la mecánica normal de los hechos. Tú sólo quieres matar el aburrimiento: yo quiero matar a Dios... (Peri Rossi 992:15)

Verdaderamente, soy un tipo adictivo. Tengo adicción al juego, al cigarrillo, a las mujeres, a la lectura del periódico, a la ducha, y a la vida: detesto la certeza de ser mortal. Pero los otros -los que no juegantienen, también, sus adicciones. Son adictos al trabajo, al dinero, al fútbol, al 
alcohol, a los medicamentos, a las hierbas, a la actualidad, o a la moda. Hay adictos a la religión, y otros, a la política. Por lo menos, las mías, son adicciones lúdicas, y no hacen daño a nadie, salvo a mí mismo. (Peri Rossi 1992:95)

El segundo aspecto, más que una intertextualidad, es la búsqueda de la identidad. De esta forma, la identidad perdida y fragmentada por la adicción, se retoma en las permanentes alusiones a Dostoievski. Así, la figura del escritor actúa como espejo, referente, justificación. El relato se narra a dos vivencias, las cuales están entrecruzadas por la obsesión y el vicio. El referente externo es utilizado para ir tejiendo la propia vida en un espejeo de desdoblamientos recurrentes. Se recobra, en fin, la condición interna, a partir de una otra imagen que, aunque ilustra las mismas miserias, no deja de ser excepcional y heroica. Lucía y Jorge, en un diálogo psicoanalítico junto a las propias reflexiones del protagonista, develan lo siguiente:

$\mathrm{Su}$ problema con el juego tampoco es muy original -responde Lucía-. Usted se remite a Dostoievski, muy a menudo, aunque posiblemente podría citar al sastre de la esquina o a la viuda del militar, que padecen la misma adicción. -El deseo de jugar no se acaba nunca -le confieso a Lucía... De modo que usted ha encontrado la fuente del deseo inagotable -comenta irónicamente Lucía-. El único límite es el cansancio, la hora de cierre o la falta de dinero, ¿no?... (Peri Rossi 1992:25)

Sin embargo, como a Dostoievski, cuando pierdo mucho dinero me atormentan los remordimientos. No sólo con relación a los mendigos, a los marginados, a los pobres y a los enfermos, sino con relación a mí mismo. Como el gran escritor ruso, no poseo fortuna propia, ni posibilidades de heredarla, ni de obtenerla por esos secretos mecanismos especuladores tan de moda en nuestros días... (Peri Rossi 1992:33-34)
Pensé en Dostoievski. Mientras por las noches jugaba, como un poseso, como un endemoniado (¿hay otra manera de jugar?) y a la mañana sufría violentos accesos de arrepentimiento, Dostoievski escribía las dramáticas páginas de El Idiota. Dos actividades intensas, obsesivas, absolutas: jugar y escribir. Lanzado a los verdes tapetes de la ruleta, donde perdía, ganaba y volvía a perder, envuelto en el torbellino de los sueños imposibles (nadie puede ganar realmente lo que desea ganar), Dostoievski jugaba hasta que el casino cerraba, y luego, sin cambiar de pulsión, sin necesidad de descansar, se dedicaba a escribir el libro más piadoso del mundo. (Peri Rossi 1992:45)

Se evidencia además en toda la trama narrativa, un deseo que adquiere las dimensiones de erotismo, de esta forma a la máquina "hay que calentarla" como a las mujeres, "Claudia me creía mujeriego, no jugador"; o, "una sala de juego tiene más disponibilidad que una mujer: siempre la encontrará abierta". La ironía, en este estatuto, asume una configuración metaliteraria que se materializa "en el arte de los finales - como- el arte de la seducción".

La imagen erótica vestida de deseo se reafirma en eso de "los hombres solemos hablar con nuestro sexo". El coito ya no es el resultado de un frenético impulso de pasión sexual, ahora es el ímpetu desbordado por unas interminables ganas de jugar. Marta, Claudia, Magda, Lucía y hasta Michel son sucesiones e idealizaciones de fugaces amoríos, instancias que movilizan en Jorge un escape, una huída hacia otra manifestación del deseo que se trasciende de la posesión de un cuerpo, a la posesión de la máquina, del sexo al juego, del semen a las monedas. Desear y jugar, copular y amar, obsesión y posesión son escenarios que se imbrican y en el cruce se diluyen, estremeciendo al 
universo narrativo que a veces es apenas una grotesca mueca de pérdidas y extravíos, en un destino que se va haciendo con los mismos materiales con los que actúa el azar. Esa es la única fe a la que se apuesta en el tejido narrativo. Valga como ejemplo de estas consideraciones la recopilación de los siguientes fragmentos:

...no veo la hora de estar a solas con una máquina tragaperras (como si fuera una amante), acariciarla, seducirla, oírla cantar, hundirle monedas como balas, despojarla, humillarla, violarla... (Peri Rossi 1992:16)

«Vamos», le digo a la luminosa tragaperras del bar. Tú y yo nos conocemos, pequeña. Tienes un programa, es decir, un secreto. Yo voy a descubrirlo. Podré más que tú. Canta, canta, princesa. Suelta tu cascada de monedas, tu chorro dorado. Sé una buena chica, de orgasmos encadenados. Las mujeres son más generosas que los hombres: alimentan, paren, protegen, consuelan. Los hombres no somos muy generosos. Damos un poco de semen nada más... Pero a mí no me está permitido forzarte, pequeña. No puedo romperte, para que me des. Tengo que respetar las reglas del juego. No puedo violarte. Debo calentarte primero, echando unas monedas, como caricias preliminares. Como el cliente a las prostitutas. (Peri Rossi 1992:24)

Lo psicoanalítico es, si se quiere, el vector cardinal que cohesiona, organiza o "explica" el universo textual. Jorge no solo va a terapia con una psicoanalista que permanentemente interpela su conciencia y lo conecta con la realidad en una suerte de remanso, de tranquilidad para soportar el peso de las presiones circundantes; sino que además, ilustra cómo el deseo insaciable se constituye en génesis de la obsesión/adicción (entendida además como una especie de autoexilio).
Esta exploración al mundo psicológico desemboca en un interés existencialista que Peri Rossi (profundizando en la obsesión del hombre), recrea, penetrando hondamente en las dimensiones interiores de un personaje que por el vértigo de los sentidos, trasgrede los límites y se asume a sí mismo como adicto. Ilusión, sueño, imagen y recuerdos son píldoras consumidas por Jorge a través de un deseo que desconfigura su identidad, haciéndole ser (y ver) como un exiliado, marginado o desprendido de todo vestigio de pasado, de toda posibilidad de futuro. En ese escudriñar los aspectos más escondidos de la conciencia de Jorge, encontramos que jugar, amar y escribir sean sus pasiones intensas, las cuales hacen estallar y estremecer su mundo psicológico caracterizado por los impulsos del goce desmedido: jugar, amar y escribir dibujan, en suma, el deseo. Afirma Olivera-Williams:

Obsesionado por el juego y el amor, el narrador se irá autodescubriendo y gracias a las sesiones con un psicoanalista irá encauzando su deseo vital hacia la escritura, una escritura como la de Dostoievski y, por supuesto, la de Peri Rossi, se vuelca hacia "Los sueños, el delirio, las fantasías", o sea, hacia el interior del individuo. (Sánchez 2007:481-485)

Lo existencialista, por su parte, esconde una carga ideológica y política que se funde con el sentido de la vida, permitiendo a Jorge, o a Peri Rossi, quizás expresar de manera transfigurada, su posición ante un mundo devastado "por las izquierdas carcomidas, por las derechas obsesivas o por los capitalismos bestiales". Así, desde una actitud militante, son comunes las instancias narrativas que, manejadas como tejido filosófico, proyectan las ideas de un yo narrador: "El servilismo importa más que la eficacia”, “A 
los 40 años todo está permitido, porque todo está perdido", "Las frustraciones aceptadas por cobardía o por falta de imaginación".

La maquinaria psicoanalítica se enfoca en el discurso y así, como un lente fotográfico, podemos ver -entre otros- el funcionamiento del complejo edípico en una relación con el protagonista que hace ausente (y ambivalente) el vínculo con el padre e ilustra un sentido casi posesivo hacia la madre. Hay un yo fragmentado que odia (imperceptiblemente) al padre por el abandono pero que lo idealiza (inalcanzablemente) porque poseyó la belleza de Michel. Ese impulso de "pertenencia" se activa ante cualquier amante que posea (o intente poseer) a la madre. La ausencia del padre, además, rompe posibilidades de identidad y "permite" la ruptura de la norma; por ello la conducta desear, jugar, gozar no tienen un referente paterno al cual poder adjudicarle la representación simbólica de la norma, del establecimiento de parámetros conductuales.

De esta forma y siguiendo algunos aportes de Freud, Jorge estaría dominado por el “principio del placer", es decir, por el Ello (forma primitiva de energía libidinal), posteriormente va efectuando transiciones hacia el Yo (se reconoce adicto) haciéndose consciente de su propia realidad y moderando/controlando su relación obsesiva y frenética con el juego hasta llegar al Súper Yo, mediante el cual se autocontrola, asume e interioriza los límites del placer y, en su afán de superar su conducta adictiva, se refugia en la posibilidad de escribir, un proceso superyoico conseguido en la construcción lingüística que se teje en la dinámica psicoanalítica (de la mano de Lucía) que actúa como subtexto, suscitando la posibilidad reconstructiva de ideales y proyectos perdidos. Otro aspecto interesante que actúa en esta obra como intertexto, sería el aporte de
Freud en torno al psicoanálisis aplicado que le permitió estudiar la conducta del mismo Dostoievski. En este aspecto, Guimón afirma lo siguiente:

En "Dostoievski y el Parricidio" Freud trata de la psicopatología de ese autor: masoquismo, sentimientos de culpa, ataques epileptoides y su ambivalencia hacia su padre. Describió en él al artista, al neurótico, al moralista y al pecador... Interpretó la adicción al juego del autor como una repetición de la compulsión a la masturbación, condicionada por el temor a su padre. (Guimón 1993:31)

Si Freud mostró cuatro facetas en el universo inconsciente de Dostoievski, Peri Rossi -en un evidente conocimiento de estas cons

trucciones- devela cómo Jorge se debate en una dinámica que pone en tensión tales facetas en su propia constitución de ser, lo cual evidencia (en Jorge y en Dostoievski) una compleja personalidad ubicada en un espacio limítrofe entre dualidades que desnudan (en ambos) a un mismo impulso, un apasionado escritor y un apasionado jugador.

\section{CONCLUSIONES}

La mirada hermenéutica realizada al arco temático exilio-azar, deja al descubierto tres escenarios propicios para la reflexión. En primer lugar, el asunto de un exilio existencial que implica necesariamente la presencia de lo otro, que no solo se asume como lo otro o lo distinto, sino que en un juego de intimidades y espejos, se le da cabida también al otro que me complementa, al otro que me define, al otro que es mi igual.

En una entrevista que Peri Rossi concediera a (San Román 1986:1042), la escritora afirmaba: “... para mí el exilio ha sido una reflexión obligada sobre lo otro, otro tiempo 
y otro espacio... Empecé a vivir en lo otro, y claro, lo otro te provoca desconfianza, tenés que establecer además algunos puentes de contacto". Esta idea de "lo otro" vendría a complementarse con esa comunión de "lo igual" que confluye, en tanto condición humana, dentro de la obra literaria, suscitando así esa búsqueda de la otredad que resuena en cada obra de arte. Le expresaba Peri Rossi a (Pérez 2005:187) que: “... el escritor tiene muchos instrumentos para escribir -la imaginación, la observación-, pero, sobre todo, tiene uno, que es la empatía... Creo que la literatura sirve para eso, para ponernos en el lugar del otro, tanto al que escribe como al lector". Al referirse a Peri Rossi, Calafell considera que estamos en presencia de:

...una autora que, a lo largo de su vasta trayectoria, ha sabido crear un universo -tanto poético como narrativo- donde identidad y alteridad se confunden, y donde lo personal deja de ser aquello que afecta a un sujeto en singular para englobar -y en muchos casos absorber- el sentir de una colectividad cifrada en un nosotros impersonal pero reconocible. No en vano, en una reciente conversación con la escritora argentina Reina Roffé, la uruguaya volvía sobre sus vivencias del pasado y concluía: "El exilio ha sido la experiencia más dolorosa de mi vida y también la más enriquecedora. Con el dolor podemos hacer dos cosas: convertirlo en odio, en rencor, o elaborarlo, sublimarlo y convertirlo en crecimiento, poesía, literatura, fraternidad, solidaridad con las víctimas. Éste fue mi camino". (Calafell 2009:129)

En segundo lugar, resulta oportuno examinar el tratamiento de lo psicoanalítico no sólo como tema dentro de los posibles universos narrativos por los que transita la pluma de Cristina Peri Rossi, sino como posibilidad de incursión a esas dimensiones psicológicas que a ratos parece una excur- sión a la zona limítrofe y obscura que ha puesto en tensión la acción de sus personajes, pero que luego nos proyecta en intacta nitidez la consciencia de un yo creador que se explora, devela y manifiesta en la obra literaria. En esta suerte, el texto pasaría a ser una especie de diván en el cual se tiende Jorge, Equis, Peri Rossi o quizá el mismo lector a narrar sus particulares historias, sus genuinas obsesiones y dudas, en fin, sus inéditas peripecias para identificar las formas cómo se desplazan esos fantasmas interiores por los laberínticos intersticios que separan y estrechan en un mismo aliento a la literatura y a la vida. Esta reflexión quedaría poéticamente retratada en intervenciones y discursos que ha expresado la misma Peri Rossi:

He dicho en una entrevista que el psicoanálisis y la literatura se parecen mucho... El paciente habla... El paciente es un narrador; el psicoanalista, un lector. En este sentido, el terreno común me parece obvio. Ambos utilizan el lenguaje, que es una colección de signos... Diría entonces que escritor es no sólo el que maneja bien su instrumento, la lengua, sino el que transfiere al papel sus emociones, procesos psíquicos, que el lector reconoce y con los que se identifica volviendo al texto una cosa viva. (Peri Rossi 1991:187)

Esta referencia nos enlaza con el último escenario reflexivo advertido en este documento y es precisamente, la relación que la autora establece con el arte a través de un ejercicio escritural que se convierte en desnudez desde las palabras. De esta forma, al sumergirnos en la obra y vivir el extravío de Equis o la ansiedad de Jorge, nos vamos topando con los desconciertos y las angustias de la autora; pero hay más, vamos escudriñando una propuesta estética que trasciende por los temas que aborda, las relaciones que establece, las profundidades 
existenciales que emergen en el texto y por la profunda visión psicológica que deambula en todo el periplo narrativo. Le decía Cristina Peri Rossi a (Pérez-Sánchez 1995:63): "La vida sin arte me parece invivible... la vida es bastante intrascendente para la mayoría de la gente. En el lugar donde alcanza otra dimensión es en el arte. En donde significa". Si bien vida y arte se entrecruzan en su obra, ese vínculo solo es posible desde una íntima relación con el lenguaje, tal como la misma Peri Rossi lo confesara a (Pérez 2014:14): “... mi única casa es la escritura... y también las palabras..., y las palabras son los objetos amados, por supuesto. Tengo una relación completamente sensual con el lenguaje, como si fuera una criatura viva."

Alrededor de estas reflexiones y como valor agregado, se puede señalar un último elemento a considerar, y es, precisamente, el empleo teórico y metodológico de la entrevista y los discursos dentro de la investigación literaria, no solo como una valiosa fuente de información, obtenida de primera mano, para aproximarnos al perfil estético y a las búsquedas y propuestas literarias de los escritores, sino como ars poética, una especie de manifiesto artístico que deja al descubierto el cruce posible entre vida y literatura, aporte valioso para configurar ese retrato humano de los creadores que se reinventa en la obra. De esta forma, la entrevista o las intervenciones hechas por los escritores más que una herramienta argumentativa dentro de la crítica literaria, puede ser advertida y examinada para idear nuevos lugares de lectura, suscitar novedosas formas de aproximarnos a la obra; o, generar múltiples rutas para la apreciación y el estudio del producto literario.

\section{REFERENCIAS BIBLIOGRÁFICAS}

Aventín, A. (2011). Algunas notas para el estudio del exilio en la obra poética de

Cristina Peri Rossi. Recuperado de https://revistas.ucm.es/index.php/RFRM/article/download/38685/37406.

Calafell, N. (2009). Atopías de ficción: el tratamiento del exilio en la narrativa breve de Cristina Peri Rossi. Etudes Romanes de Brno, (2), 129-139. Recuperado de https://dialnet.unirioja.es/descarga/articulo/4267458.pdf

Cid, J. (2012). Indefinición sexual y disciplinamiento de un personaje Equis. Literatura y lingüística, (25), 83-98. Recuperado de http://www.scielo.cl/pdf/lyl/n25/art05.pdf

Corbatta, J. (1994). Metáforas del exilio e intertextualidad en "La nave de los locos" de Cristina Peri Rossi y "Novela negra con argentinos" de Luisa Valenzuela. Revista hispánica moderna, (XLVII), 167-183.

Gallego, F. (2014). Literatura y psicoanálisis: entre el ser y el semblante. Arjé, 8(14), 173-185.

Guimón, J. (1993). Psicoanálisis y literatura. Barcelona, España: Editorial Kairós.

Peri Rossi, C. (1991). Acerca de la escritura. Zaragoza, España: Universidad de Zaragosa.

Peri Rossi, C. (1992). La última noche de Dostoievski. Madrid, España: Grijalbo Mondadori.

Pérez, A. (2005). Del deseo y sus accesos: una entrevista a Cristina Peri Rossi. Lectora, (11), 181-193. Recuperado de www.raco.cat/index.php/Lectora/article/download/205535/284734

Pérez, C. (2014). Allá, en Barcelona. Entrevista a Cristina Peri Rossi. En Revista arbitrada de la Asociación de Profesores 


\section{Unach}

de Literatura del Uruguay, (8), 13-19. Recuperado de http://www.edicionescalamo.es/uploads/ficheros/noticias/documento/201410/documento-noticia-es.pdf

Pérez-Sánchez, G. (1995). Entrevista a Cristina Peri Rossi. Hispamerica, 24(72), 59-72. Recuperado de https://www.jstor.org/stable/20539872?seq=1\#page_scan_tab_contents

Ricoeur, P. (1975). La metáfora viva. Madrid, España: Ediciones Cristiandad.

San Román, G. (1986). Entrevista a Cristina Peri Rossi. Revista Iberoamericana, 58(160-161), 1041-1048. Recuperado de http://revista-iberoamericana.pitt.edu/ojs/index.php/Iberoamericana/article/download/5090/5248+\&c $\mathrm{d}=1 \& \mathrm{hl}=\mathrm{es}-419 \& \mathrm{ct}=\mathrm{clnk} \& \mathrm{gl}=\mathrm{ve}$

Sánchez, L. (2007). La narrativa de Cristina Peri Rossi (Tesis de doctorado inédita). Universidad de Coruña, España.

Szurmuk, M. (2003). Extranjería y exilio en La nave de los locos de Cristina Peri Rossi. En Blanck - Cereijido, F. \& P. Yankelevich (eds.). El otro, el extranjero (pp. 89-107). Buenos Aires, Argentina: Libros del Zorzal.

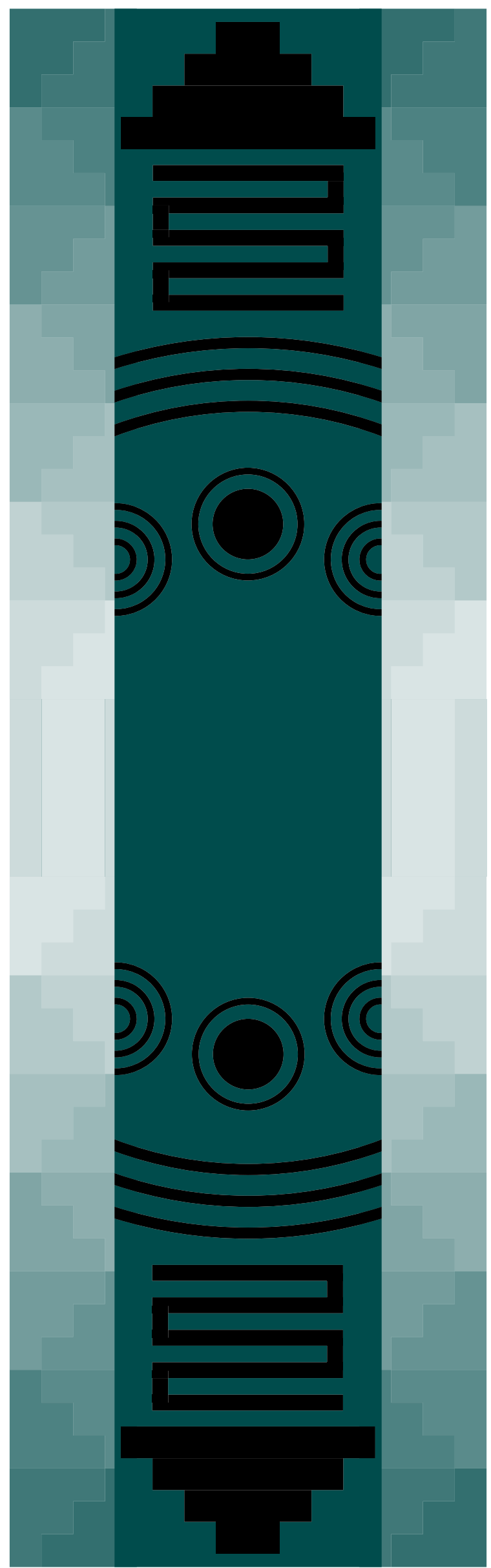

